\title{
Prevalence of gastrointestinal helminth infections in ovine population of Kashmir Valley
}

\author{
S. R. Tramboo, R. A. Shahardar, I. M. Allaie, Z. A. Wani and M. S. Bushra
}

\begin{abstract}
Division of Veterinary Parasitology, Faculty of Veterinary Science and Animal Husbandry, Sher-E-Kashmir University of Agricultural Sciences and Technology of Kashmir, Shuhama Campus, Alusteng, Srinagar - 190006 , Jammu and Kashmir, India.

Corresponding author: I. M. Allaie, e-mail: idreesmeharaj@skuastkashmir.ac.in, SRT: shahana_qx@yahoo.com, RAS: rafiqshahardar@gmail.com, ZAW: zahoorwani_103@yahoo.co.in, MSB: bushraashah@gmail.com

Received: 25-03-2015, Revised: 08-08-2015, Accepted: 18-08-2015, Published online: 17-10-2015
\end{abstract}

doi: 10.14202/vetworld.2015.1199-1204 How to cite this article: Tramboo SR, Shahardar RA, Allaie IM, Wani ZA, Bushra MS (2015) Prevalence of gastrointestinal helminth infections in ovine population of Kashmir Valley, Veterinary World 8(10): 1199-1204.

\begin{abstract}
Aim: Gastrointestinal (GI) helminth parasitism is one of the major constraints for profitable sheep production. Due to variations in the prevalence of GI helminths from region to region, it becomes important to map out accurately the parasitic fauna of a particular region for development of suitable control measures.

Materials and Methods: An extensive study of GI helminths was carried out in Budgam district of Kashmir Valley over a period of 1 year. A total of 1200 fresh ovine faecal samples from both sexes of young ones and adults were collected in sterilized plastic bags and examined by standard sedimentation and floatation techniques. Positive faecal samples (15-20\%) in each season were examined by Stoll's dilution method to determine the parasitic load. A total of 120 faecal samples (30 samples in each season) positive for strongyle eggs were subjected to coproculture using Petridish method and the third stage larvae were harvested to find out prevalence of different genera of strongyle worms.

Results: The overall prevalence of GI helminths was found to be $77 \%$ with platyhelminths and nemathelminthes in 26.58 and $60.92 \%$ animals, respectively. The overall prevalence of mixed GI helminths was found to be $8.67 \%$. Eggs of various helminths encountered in the present study were those of Fasciola spp. (3.58\%), Dicrocoelium spp. (11.58\%), paramphistomes (4.83\%), Moniezia spp. (7.92\%), strongyle worms including Nematodirus spp. (57.75\%), Strongyloides spp. (1.67\%), and Trichuris spp. (1.5\%). On coprocultural examination Haemonchus spp. (55\%) was found to be most predominant strongyle worm followed by Trichostrongylus spp. (17.5\%), Ostertagia spp. (11.67\%), Oesophagostomum spp. (9.17\%), and Chabertia spp. (6.67\%). On seasonal basis, highest prevalence of GI helminths was recorded in summer $(83.00 \%)$ followed by spring $(78.67 \%)$, winter $(76.33 \%)$, and autumn $(70.00 \%)$, the difference being statistically nonsignificant ( $\mathrm{p}>0.05)$. The prevalence of platyhelminths (Fasciola spp., Dicrocoelium spp. and Moniezia spp.) was found to be non-significantly higher in winter, but paramphistomes showed the highest prevalence in the summer season. Nemathelminth infection was found highest in summer season and lowest during the winter season. Eggs per gram (EPG) ranged from 0 to 1800 , and an average EPG count was found to be $454.35 \pm 27.85$. EPG was found to be highest in summer $(684.00 \pm 69.83)$ and lowest in winter $(202.38 \pm 18.82)$. The overall prevalence of GI helminths was found more in adult sheep $(83.00 \%)$ compared to young ones $(53.11 \%)$, the difference being statistically significant $(\mathrm{p}<0.05)$. Similarly, the prevalence of helminths was found to be higher in females $(78.32 \%)$ as compared to males $(72.97 \%)$, the variation being statistically non-significant ( $\mathrm{p}>0.05)$.
\end{abstract}

Conclusion: Seasonal variation plays an important role in the prevalence of GI helminths in addition to age and sex of the animal.

Keywords: coproculture, gastrointestinal, Kashmir, nemathelminths, ovine, prevalence, platyhelminths.

\section{Introduction}

Sheep sufficing a multipurpose need of wool, milk, skin, meat, and manure is the main source of income to the marginal farmers of the country [1]. Sheep are highly susceptible to gastrointestinal (GI) parasitosis, thereby inflicting losses through morbidity, mortality, reduced feed conversion ratio, poor wool or meat quality, and by way of costs incurred on treatment and control [2]. In India, helminth diseases alone are responsible for 5\% mortality and more than $10 \%$ morbidity in sheep [3].

Copyright: The authors. This article is an open access article licensed under the terms of the Creative Commons Attributin License (http:// creative commons.org/licenses/by/2.0) which permits unrestricted use, distribution and reproduction in any medium, provided the work is properly cited.
The overall development of the rural hilly areas could not be achieved by neglecting the development of the agricultural commodities such as sheep and goats [4].

The prevalence of these GI helminths varies from region to region depending upon the local climatic conditions of the region and managemental practices adopted. As such the parasitic fauna of each region should be mapped out accurately for the development of various control measures. In Kashmir Valley, the incidence of parasitic infection in sheep has been reported by various workers [4-11] but these studies are restricted to either organized farms or to sheep flocks in and around Srinagar city, and no such study have been carried out in locally reared sheep of Budgam district in particular. 
In our study, GI parasitism in ovine population was thoroughly screened over a period of 1 year in all the tehsils of Budgam district of Kashmir Valley.

\section{Materials and Methods \\ Ethical approval}

The present study was based on the laboratory examination of faeces of sheep and no experiment was conducted on the animals. So, permission is not necessary for such type of study. However, samples were collected as per standard sample collection procedure.

\section{Study area}

Budgam is bounded by Baramulla and Srinagar in the north, Pulwama in the south and Poonch border in the southwest. It is situated at an average altitude of $5281 \mathrm{ft}$ above mean sea level and at $75^{\circ}$ East longitude and $34^{\circ}$ North latitude. The topography of the district is mixed with both mountainous and plain areas. Administratively, this district is divided into six tehsils namely Chari - Sharief, Beerwah, Budgam, Chadoora, Khag, and Khan sahib and covers an area of $1,371 \mathrm{Km}^{2}$. The climate is of the temperate type with the upper reaches receiving heavy snowfall in winter. The maximum temperature varies from $12.83^{\circ} \mathrm{C}$ to $34.17^{\circ} \mathrm{C}$, and minimum temperature varies from $-4.47^{\circ} \mathrm{C}$ to $12.13^{\circ} \mathrm{C}$. Total rainfall and relative humidity varies between 35.87 and $90.33 \mathrm{~mm}$ and 66.74 and $80.18 \%$, respectively.

\section{Sample collection and processing}

A total of 1200 samples were collected from all the six tehsils of district Budgam for a period of 1 year. The samples were collected directly from rectum and brought to the laboratory in mini zip locked polythene bags for examination. During collection, name of the owner, place of collection, age, and sex of the animals were recorded. On the basis of age, animals were classified as adults (age $>1$ year) and young (age $<$ 1 year). These samples were collected during all the four seasons viz; summer (June-August), autumn (September-November), winter (December-February), and spring (March-May) with 300 samples in each season. Samples were preserved at refrigeration temperature $\left(4^{\circ} \mathrm{C}\right)$ till examination and examined within 2-3 days after collection. The samples were examined qualitatively using sedimentation and floatation techniques for evaluating the incidence of infection [12]. Randomly selected $15-20 \%$ faecal samples were examined in each season by Stoll's dilution method to determine the parasitic load, i.e. eggs per gram (EPG) of faeces [12]. A total of 120 faecal samples (30 samples in each season) positive for strongyle eggs were subjected to coproculture using petridish method [13] for harvesting third stage larvae. The harvested larvae were examined using key morphological differences described by Van-Wyk et al. [14] to work out the prevalence of different genera of strongyle worms.

\section{Statistical analysis}

The results were subjected to standard statistical analysis as per Snedecor and Cochran [15].

\section{Results and Discussion}

In this study, the overall prevalence of GI helminths in sheep of Budgam district was found to be $77.00 \%$ with mixed infection in $8.67 \%$ animals (Table-1). Average EPG was found to be $454.35 \pm 27.85$ (EPG range: 0-1800) (Table-2). On qualitative examination, low level of strongyle worm infection was observed, which on quantitative examination (Stolls dilution method) revealed zero (0) EPG. Almost similar incidence has been reported by Pandit et al. [6] (65.4\% overall prevalence) and Bhat et al. [11] (62.9\%overall prevalence) in sheep of Kashmir Valley and Yadav et al. [16] (83.24\% overall prevalence) and Khajuria et al. [17] (68.54\% overall prevalence) in sheep of Jammu, respectively. In this study, the overall prevalence of platyhelminths was $26.58 \%$ with trematodes and cestodes having a prevalence of $19.67 \%$ and $7.92 \%$, respectively. Prevalence of Dicrocoelium spp. $(11.58 \%)$ was highest followed by paramphistomes (4.83\%), while Fasciola spp. (3.58\%) had the lowest prevalence. Moniezia spp. was the only cestode parasite found in the present study with a percentage prevalence of 7.92 (Table-1). Our observations are almost similar to Shahnawaz et al. [9] who reported an overall prevalence of platyhelminths to be $28.50 \%$ with trematodes and cestodes in $18.66 \%$ and $11.83 \%$ sheep respectively in Ganderbal district of Kashmir Valley. The overall prevalence of nemathelminths in this study was $60.92 \%$ with a maximum prevalence of Strongyle worms (57.75\%) followed by Strongyloides spp. (1.67\%) and Trichuris spp. (1.50\%) (Table-1). The results of the present investigation are in close approximation to the findings of Tariq et al. [8] who reported $61.6 \%$ overall prevalence of nemathelminth parasites in sheep of Kashmir Valley. Predominance of strongyle group of worms over other nematodes noted in this study has also been reported by Pandit et al. [6,7] and Wani et al. [10] in sheep of Kashmir Valley as well as Khajuria and Kapoor [18] and Yadav et al. [16] in sheep of Jammu region. Kumar et al. [19] reported strongyle worm infection as a major cause of GI tract disorders of sheep followed by Strongyloides spp. in Sheep Breeding Farm, Lala Lajpat Rai University of Veterinary and Animal Sciences, Hisar, Haryana.

Non-significantly $(\mathrm{p}>0.05)$ prevalence of GI helminths was found highest in summer season $(83.00 \%)$ followed by spring $(78.67 \%)$, winter $(76.33 \%)$, and lowest in autumn $(70.00 \%)$. The higher platyhelminth infection rate was found in winter $(35.67 \%)$ followed by spring $(27.33 \%)$, summer $(24.33 \%)$, and autumn (19\%). However, the difference was significant $(p<0.05)$ between autumn and winter seasons. In this study, the highest infection rate of nemathelminths was observed in summer $(67.67 \%)$ followed by spring $(63.33 \%)$, autumn $(57.67 \%)$, and winter (55\%) (Table-1). Average EPG was found highest in summer season, $684 \pm 69.83$ (EPG range: $0-1800$ ) 


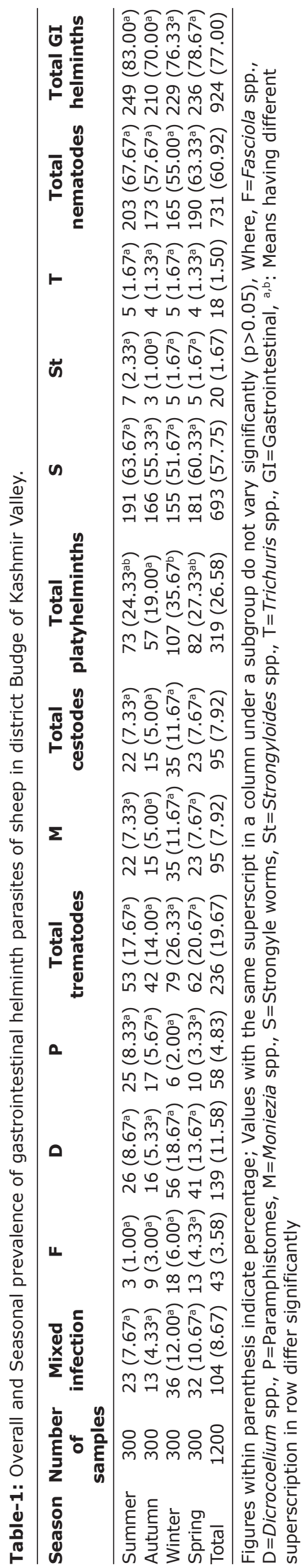

followed by spring $577.08 \pm 48.76$ (EPG range: $0-800$ ); autumn $300.00 \pm 24.33$ (EPG range: 0-500), and winter $202.38 \pm 18.82$ (EPG range: $0-300$ ), the variation being statistically significant $(\mathrm{p}<0.05) \quad($ Table-2). This observation goes in agreement with Swarnkar et al. [20] who observed peak parasitism in the summer season. Yadav et al. [16] and Sharma et al. [21] also observed the highest EPG in rainy season with the lowest EPG in winter season in sheep of Jammu and Palam Valley of north western Himalayan region, respectively. The highest rate of infection in summer is due to very favorable environmental conditions (temperature - maximum $34.17^{\circ} \mathrm{C}$, minimum $12.13^{\circ} \mathrm{C}$; $35.87 \mathrm{~mm}$ rainfall, and $66.74 \%$ relative humidity) for hatching of eggs and development of free living larval stages. In spring (temperature - maximum $25.0^{\circ} \mathrm{C}$, minimum $2.0^{\circ} \mathrm{C} ; 75.30 \mathrm{~mm}$ rainfall, and $67.14 \%$ relative humidity), and autumn (temperature - maximum $27.33^{\circ} \mathrm{C}$, minimum $1.57^{\circ} \mathrm{C}$; $49.37 \mathrm{~mm}$ rainfall and $71.92 \%$ relative humidity), due to moderate temperature hatching and development of free living larval stages gets comparatively delayed and in winter (temperature - maximum $12.83^{\circ} \mathrm{C}$, minimum $-4.47^{\circ} \mathrm{C}$; $90.33 \mathrm{~mm}$ rainfall, and $80.18 \%$ relative humidity) due to extremely low environmental temperature, hypobiosis occurs and therefore there is reduction in faecal egg counts. Trematodes showed a similar trend with the highest prevalence of $26.33 \%$ in winter followed by $20.67 \%, 17.67 \%$, and $14.00 \%$ in spring, summer, and autumn, respectively, seasonal variation being non-significant $(\mathrm{p}>0.05)$ except for paramphistomes which showed a different seasonal activity with the highest prevalence of $8.33 \%$ in summer followed by $5.67 \%, 3.33 \%$, and $2.00 \%$ in autumn, spring, and winter, respectively (Table-1 and Figure-1). The highest prevalence of Fasciola spp. in winter is due to grazing of sheep in harvested paddy fields during autumn

Table-2: Age-wise and seasonal comparison of a parasitic load of GI helminth parasites of sheep in Budgam district of Kashmir.

\begin{tabular}{llccl}
\hline Season & Host & $\begin{array}{c}\text { Number of } \\
\text { samples } \\
\text { screened }\end{array}$ & $\begin{array}{c}\text { EPG } \\
\text { range }\end{array}$ & Mean EPG \\
\hline Summer & Adult & 31 & $0-1700$ & $754.84 \pm 70.46$ \\
& Young & 19 & $0-1800$ & $568.42 \pm 142.26$ \\
& Total & 50 & $0-1800$ & $684.00^{\mathrm{a}} \pm 69.83$ \\
Autumn & Adult & 28 & $0-500$ & $321.43 \pm 25.90$ \\
& Young & 16 & $0-500$ & $262.50 \pm 49.05$ \\
& Total & 44 & $0-500$ & $300.00^{\mathrm{b}} \pm 24.33$ \\
Winter & Adult & 27 & $0-300$ & $211.11 \pm 22.85$ \\
& Young & 15 & $0-300$ & $186.67 \pm 33.62$ \\
& Total & 42 & $0-300$ & $202.38^{\mathrm{b}} \pm 18.82$ \\
\multirow{5}{*}{ Oving } & Adult & 32 & $0-900$ & $587.50 \pm 61.69$ \\
& Young & 16 & $0-800$ & $556.25 \pm 81.12$ \\
& Total & 48 & $0-800$ & $577.08^{\mathrm{a}} \pm 48.76$ \\
& Adult & 118 & $0-1700$ & $482.20^{\mathrm{a}} \pm 32.56$ \\
& Young & 66 & $0-1800$ & $404.55^{\mathrm{a}} \pm 51.16$ \\
& Total & 184 & $0-1800$ & $454.35 \pm 27.85$ \\
\hline
\end{tabular}

EPG: Eggs per gram, ${ }^{\mathrm{a}, \mathrm{b}}$ : Means having different superscription in row differ significantly 
after return from alpine pastures where they pick up the infection and worms reach to sexual maturity during winter and thereby, start passing eggs in faeces. The higher prevalence rate of paramphistomes during summer season is logistic since during the drier months snail population becomes concentrated around areas of natural water which also have the most palatable grazing, thus there is concentration of snails, metacercariae, and animals over a small area leading to heavy infection [12]. Godara et al. [22] also recorded a higher percentage of sheep positive for paramphistomes in autumn season as compared to winter. Non-significantly ( $\mathrm{p}>0.05)$, Moniezia spp. was found to be highest in winter $(11.67 \%)$ followed by spring $(7.67 \%)$, summer $(7.33 \%)$, and autumn (5\%) (Table-1 and Figure-1).

Significantly, $(\mathrm{p}<0.05)$ higher prevalence rate of GI helminths $(83.00 \%)$ was observed in adult sheep compared to lambs and hoggets $(53.11 \%)$. The higher prevalence rate of trematodes was observed in adult sheep compared to lambs and hoggets, the difference being statistically non-significant ( $\mathrm{p}>0.05)$. However, Moniezia spp. infection was more prevalent in the younger group $(12.45 \%$ ) as against $6.78 \%$ in adult age group, the difference being statistically non-significant ( $p>0.05)$. Nemathelminths were found higher in adult sheep $(65.80 \%)$ in comparison to young ones $(41.49 \%)$, the variation being statistically significant $(p<0.05)$ (Figure-2). Non-significantly $(p>0.05), E P G$ was found higher in adult sheep $(482.20 \pm 32.56)$ as compared to young sheep (404.55 \pm 51.16$)$ (Table-2). Our observations of higher EPG in adult sheep as compared to young sheep are in agreement with those of Swarankar et al. [20] and Yadav et al. [16] who reported higher prevalence of helminths in adult sheep compared to young ones in Rajasthan and Jammu, respectively. Shahnawaz et al. [9] also reported higher trematode infections in adults as compared to young sheep but higher Moniezia infection in lambs as compared to adult sheep. The highest prevalence of helminth parasites in adult animals compared to young ones is due to their long exposure to infective stages in grazing fields and also because the sheep reared by farmers are not properly dosed or underdosed which results in build-up of infection. Low prevalence of Moniezia spp. in adults compared to young ones in the present study may be attributed to previous infection and age of host which affords some protection against reinfection, thereby causing severe monieziosis in young animals [12]. Wani et al. [10] has also reported a higher prevalence of nemathelminths in adult sheep compared to young ones in Ganderbal district of Kashmir Valley.

The prevalence of helminth parasites recorded in this study viz. Fasciola spp. (2.7\% in males and 3.87\% in females), Dicrocoelium spp. (10.81\% in males and $11.84 \%$ in females), paramphistomes $(4.05 \%$ in males and $5.09 \%$ in females), Moniezia spp. (4.05\% in males and $9.18 \%$ in females), strongyle worms $(54.39 \%$ in males and $58.85 \%$ in females), Strongyloides spp. (1.01\% in males and $1.88 \%$ in females), and Trichuris spp. ( $0.68 \%$ in males and $1.77 \%$ in females) were higher in females compared to males, the variation being statistically non-significant ( $p>0.05$ ) (Figure-3). The higher infection rate of parasites in female sheep are in line with Mbap and Chiroma [23] who found female sheep more susceptible to infection than males. The higher infection rate of platyhelminths and nemathelminths in females has also been reported by Shahnawaz et al. [9] and Wani et al. [10], respectively in Ganderbal district of Kashmir Valley. Significantly, $(p<0.05)$ an average EPG $(490.65 \pm 32.64)$ was found to be higher in females than males $(342.22 \pm 49.90)$.

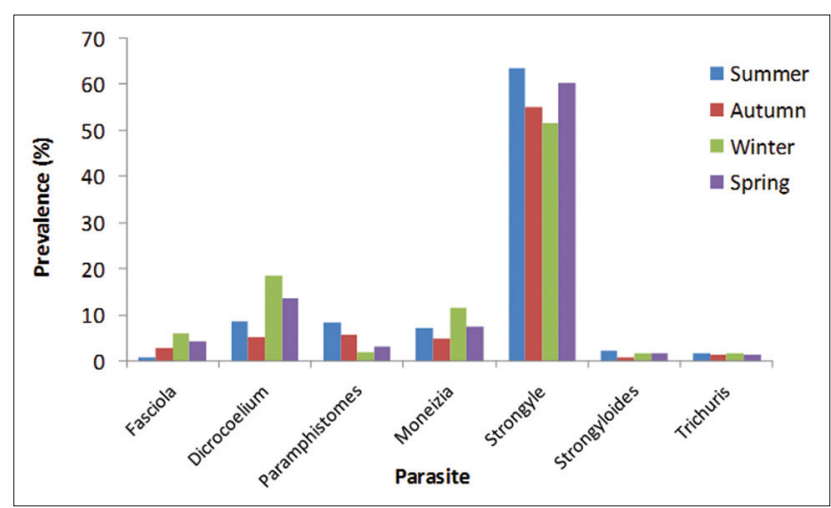

Figure-1: Seasonal prevalence of gastrointestinal helminths of sheep in Budgam, Kashmir.

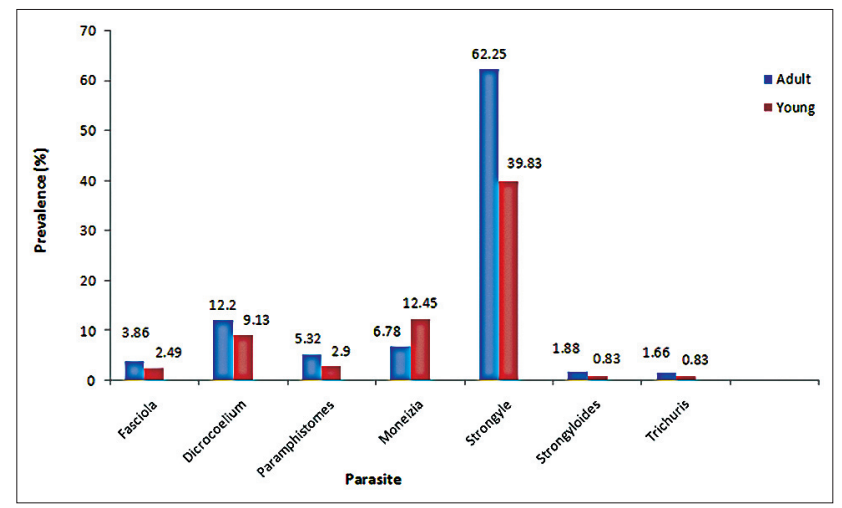

Figure-2: Age-wise prevalence of gastrointestinal helminthes of sheep in Budgam, Kashmir.

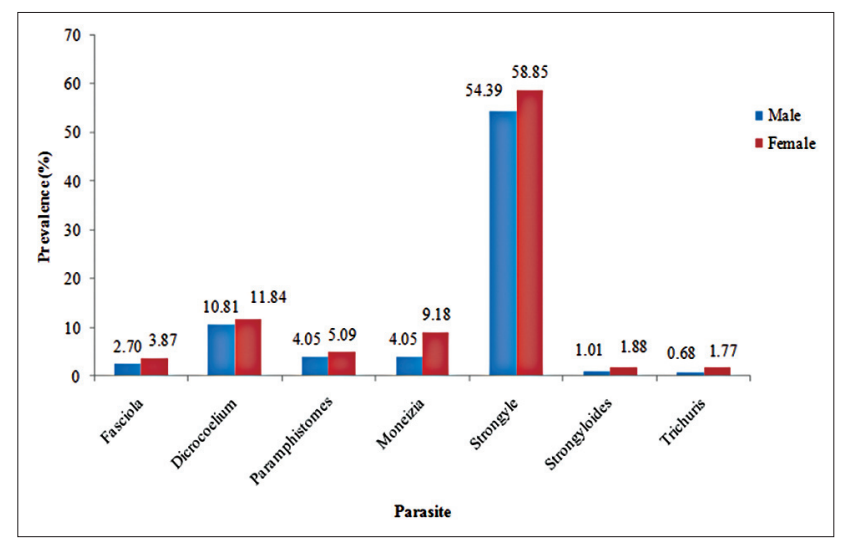

Figure-3: Sex-wise prevalence of gastrointestinal helminths of sheep in Budgam, Kashmir. 
The reason can be attributed to post parturition and lactation stress leading to high shedding of eggs of GI nematodes, thereby increasing pasture infectivity. In lactating animals, there is an increase in susceptibility of ewes to newly acquired the infection during the periparturient period [24]. Highest prevalence (18.67\%) of Dicrocoelium spp. in winter has also been reported by Shahnawaz et al. [9] and can be attributed to the fact that animals pick up the infection during the summer and autumn seasons from paddy fields and apple orchids and the parasites reach to sexual maturity in winter season.

On coprocultural examination of strongyle worms, Haemonchus spp. (55.00\%) was found to be most predominant strongyle worm followed by Trichostrongylus spp. (17.50\%), Ostertagia spp. (11.67\%), Oesophagostomum spp. (9.17\%), and Chabertia spp. (6.67\%). The predominance of Haemonchus spp. over other strongyle worms has also been reported by Tariq et al. [8] and Wani et al. [10] in Kashmir Valley. Domke et al. [25] and Kuchai et al. [26] also recorded Haemonchus to be one of the most prevalent strongyle worms in sheep from Norway and Ladakh respectively. Singh et al. [27] reported Haemonchus as the main GI parasite in sheep and goats in and around Mathura, India. The reason for this predominance can be due to the fact that Haemonchus females are basically prolific egg layers (laying about 10,000 eggs a day).

\section{Conclusion}

The present communication documents prevalence of GI helminths in sheep of Budgam district of Kashmir Valley. Seasonal variation plays an important role in the prevalence of GI helminths in addition to age and sex of the animal. The overall high prevalence of gastrointestinal helminth infection $(77 \%)$ in Budgam district of Kashmir Valley can be attributed to poor managemental techniques that are being practiced by the local farmers. Besides poor managemental practices, lack of pastures in the valley makes the animals to graze the same land time and again, thereby resulting in building of infections in these animals. Also, animals were not previously dewormed, and lack of knowledge of proper dosing methods by the sheep owners keep infection rate high in these animals. Based on the research findings of this study, it is concluded that the broad spectrum anthelmintics which are effective against both platyhelminths and nemathelminths may be used in prophylactic treatment of animals twice (early spring and late autumn) or thrice in a year (early spring, late summer and late autumn) to prevent production losses in the Budgam district of Kashmir Valley.

\section{Authors' Contributions}

SRT processed out the samples and prepared the manuscript under the guidance of RAS and IMA. RAS designed the study. IMA provided technical support and gave final shape to the manuscript. ZAW and BMS provided manual help. All authors read and approved the final manuscript.

\section{Acknowledgments}

The authors are highly thankful to Director of Research, SKUAST-K, Shalimar Campus for providing the necessary facilities and funds to carry out this research. The authors express their gratitude to Budgam wing of Department of Sheep Husbandry, Kashmir for allowing and assisting in the smooth collection of samples. The authors are highly thankful to Prof. T.A.S. Ganaie, Head, Division of Animal Genetics and Breeding, SKUAST-K for statistical analysis of the data. The help rendered by the officials of the Division of Veterinary Parasitology is also great fully acknowledged.

\section{Competing Interests}

The authors declare that they have no competing interests.

\section{References}

1. Pathak, A.K. and Pal, S. (2008) Seasonal prevalence of gastrointestinal parasites in goats from durg district of Chhattisgarh. Vet. World, 1(5): 136-137.

2. Nwosu, C.O., Madu, P.P. and Richards, W.S. (2007) Prevalence and seasonal changes in the population of gastrointestinal nematodes of small ruminants in the semi-arid zone of North-Eastern Nigeria. Vet. Parasitol., 144(1-2): 118-124.

3. Chakraborty, D. and Lodhi, C. (1994) Studies on blood and biochemical profiles in naturally infected goats. Indian Vet. J., 3: 286-288.

4. Ahmad, L.B., Chisti, M.Z., Fayaz, A. and Hidayatullah, T. (2012) A survey of gastrointestinal helminth parasites of slaughtered sheep and goats in Ganderbal, Kashmir. Glob. Vet., 8(4): 338-341.

5. Makhdoomi, D.M., Shugufta, N., Banday, S.D. and Moulvi, B. (1995) Incidence of different ovine gastrointestinal parasites in Kashmir. Indian Vet. J., 72: 898-900.

6. Pandit, B.A., Shahardar, R.A., Bhat, A.S. and Darzi, M.M. (2003a) Prevalence of gastrointestinal parasitic infection in sheep of Kashmir Valley under different management practices. Appl. Biol. Res., 5(11): 1-5.

7. Pandit, B.A., Shahardar, R.A., Darzi, M.M., Banday, M.A.A. and Bhat, A.S. (2003b) Survey of gastrointestinal nematodes in sheep of Kashmir Valley. Indian J. Small Rumin., 9: 39-42.

8. Tariq, K.A., Chisti, M.Z., Ahmad, F. and Shawl, A.S. (2008) Epidemiology of gastrointestinal nematodes of sheep managed under traditional husbandry system in Kashmir Valley. Vet. Parasitol., 158(1-2): 138-143.

9. Shahnawaz, M., Shahardar, R.A. and Wani, Z.A. (2011) Seasonal prevalence of platyhelminthosis of sheep in Ganderbal area of Kashmir Valley. J. Vet. Parasitol., 25: 59-62.

10. Wani, Z.A., Shahardar, R.A. and Shahnawaz, M. (2011). Prevalence of nemathelminth parasites in sheep of Ganderbal district of Kashmir Valley. J. Vet. Parasitol., 25(1): 26-29.

11. Bhat, S.A., Mir, M.R., Qadir, S., Allaie, I.M., Khan, H.M., Husain, I. and Sheikh, B.A. (2012) Prevalence of gastrointestinal parasitic infections in Sheep of Kashmir Valley of India. Vet. World, 5(11): 667-671.

12. Soulsby, E.J.L. (1982) Helminths, Arthopods and Protozoa of Domesticated Animals. $7^{\text {th }}$ ed. ELBS and Baillere Tindal, London. 
13. Sahai, B.N. (1960) Studies on host specificity of Haemonchus spp. in sheep and buffaloes. M.V. Sc. Thesis, Indian Veterinary Research Institute, Izat Nagar.

14. Van-Wyk, J.A., Cabaret, J. and Michael, L.M. (2004) Morphological identification of nematode larva of small ruminants and cattle simplified. Vet. Parasitol.,119(4): 277-306.

15. Snedecor, G.W. and Cochran, W.G. (1994) Statistical Methods. $8^{\text {th }}$ ed. Iowa State University Press, IOWA, USA.

16. Yadav, A., Khajuria, J.K. and Raina, A.K. (2006) Seasonal prevalence of gastrointestinal parasites in sheep and goats of Jammu. J. Vet. Parasitol., 20(1): 65-68.

17. Khajuria, J.K., Katoch, R., Yadav, A., Godara, R., Gupta, S.K. and Singh, A. (2013) Seasonal prevalence of gastrointestinal helminths in sheep and goats of middle-agro climatic zone of Jammu province. J. Parasitol. Dis., 37(1): 21-25.

18. Khajuria, J.K. and Kapoor, P.R. (2003) Prevalence of parasites in sheep and goats at Kathua-Jammu. J. Vet. Parasitol., 17: 121-126.

19. Kumar, S., Jakhar, K.K., Singh, S., Potliya, S., Kumar, K. and Pal, M. (2015) Clinicopathological studies of gastrointestinal tract disorders in sheep with parasitic infection. Vet. World, 8: 29-32.

20. Swarnkar, C.P., Singh, D., Srivastava, C.P., Bhagwan, P.S.K. and Dimri, U. (1996) A restrospective study on ovine gastrointestinal helminthoses under semi - arid conditions.
J. Vet. Parasitol., 10: 15-21.

21. Sharma, D., Katoch, R. and Agnihotri, R.K. (2007) Gastrointestinal helminths in Gaddi sheep. J. Vet. Parasitol., 21: 141-143.

22. Godara, R., Katoch, R., Yadav, A. and Rastogi, A. (2014) Epidemiology of paramphistomosis in sheep and goats in Jammu, India. J. Parasitol. Dis., 38(4): 423-428.

23. Mbap, S.T. and Chiroma, B.Y. (1998) The effects of breed and environmental factors on helminth infection of sheep in Bauchi, Nigeria. In: Proceedings of the $6^{\text {th }}$ World Congress on Genetics Applied to Livestock Production. Armidale, NSW, Australia.

24. Shubber, A.H., Lloyd, S. and Soulsby, E.J.L. (1981) Infection with gastrointestinal helminths: Effect of lactation and maternal transfer of immunity. Z. Parasitenkd., 65(2): 181-189.

25. Domke, A.V.M., Chartier, C., Gjerde, B., Leine, N., Vatn, S. and Stuen, S. (2013) Prevalence of gastrointestinal helminths, lungworms and liver fluke in sheep and goats in Norway. Vet. Parasitol., 194(1): 40-48.

26. Kuchai, J.A., Chishti, M.Z., Ahmad, F., Mir, M.R. and. Darv, J.A. (2013) Impact of health status and species of the host on prevalence of helminthiasis in sheep and goats of Ladakh. Int. J. Agron. Plant Prod., 4(5): 869-872.

27. Singh, V., Varshney, P., Dash, S.K. and Lal, H.P. (2013) Prevalence of gastrointestinal parasites in sheep and goats in and around Mathura, India. Vet. World, 6(5): 260-262. 